Article

\title{
Effect of the Urbanization of Wetlands on Microclimate: A Case Study of Xixi Wetland, Hangzhou, China
}

\author{
Wei Zhang ${ }^{1, *}$, Yubi Zhu ${ }^{2}$ and Jingang Jiang ${ }^{3}$ \\ 1 School of Geographical Sciences, Southwest University, Chongqing 400715, China \\ 2 College of Economics and Management, Southwest University, Chongqing 400715, China; \\ Zhuyb1965@sina.com \\ 3 Ocean College, Zhejiang University, Hangzhou 310058, China; gangzg@zju.edu.cn \\ * Correspondence: zwei1997@swu.edu.cn; Tel.: +86-23-68-253-912
}

Academic Editor: Vincenzo Torretta

Received: 3 July 2016; Accepted: 29 August 2016; Published: 5 September 2016

\begin{abstract}
Urbanization affects the microclimate and forms a unique urban climate environment. To deepen the understanding on the microclimate regulation function of an urban wetland, this study analyzed the influence of a suburb wetland's urbanization process on the local climate through contrast observations of the protected wetland area and the former wetland area in Xixi wetland. Results show that the urbanization of suburb wetlands has an impact on the local microclimate and decreases human comfort, and that wetlands can effectively regulate the microclimate. The fragmentation of urban wetlands caused by urban sprawl decreases their microclimate regulation function, a decrease that is particularly evident in summer. Additionally, wetlands stabilize the microclimate in all seasons. For every land cover type in wetlands, vegetation has a better stabilizing effect on temperature, whereas a water body has a better stabilizing effect on wind speed and humidity. Meteorological conditions also affect the microclimate regulation function of wetlands. Temperature, humidity, atmospheric pressure, and wind speed influence the cooling function of urban wetlands, while solar radiation modifies the humidifying function of urban wetlands.
\end{abstract}

Keywords: urbanization; urban wetland; microclimate; Hangzhou; China

PACS: 92.60.Kc

\section{Introduction}

Many developing countries are currently in the midst of rapid urbanization and industrialization $[1,2]$. However, despite the numerous economic opportunities brought about by rapid urbanization, it still causes a series of environmental problems because of fundamental changes in the biotic and abiotic environments in and around cities [3], such as deterioration of water quality [4,5], decrease of cultivated land [6,7], and increased air pollution [8].

Urbanization greatly influences urban climate as well. The characteristics of an urban climate can be summarized as the "five island effects", namely, urban heat island (UHI) [9], urban humid island [10], urban arid island [11], urban turbid island [12], and urban rainy island [13,14]. UHI is the most prominent characteristic of urban climate [15]. The intensity of UHI is usually proportional to the population size and built-up area of a city, averages $2{ }^{\circ} \mathrm{C}$, and can reach as high as $10^{\circ} \mathrm{C}$ [15].

Wetlands have important functions in climate regulation [16,17]. The microclimate effects of wetlands are mainly realized through evapotranspiration and heat storage [18]. On the one hand, the thermal capacity of water is greater than those of soil, rock, and vegetation. In comparison with land, 
water bodies can store more heat and decelerate temperature variation; thus, wetlands can regulate the surrounding climate. On the other hand, the temperature difference between water bodies and land causes local lake breeze circulation and increases the average wind speed in a wetland region [19]. At the same time, the evaporation and heat storage of water bodies are generally larger than those of the land surface; these processes can take away ambient heat and increase air humidity in wetland regions $[20,21]$.

Urban climate anomalies caused by rapid urbanization attract numerous scholars to study the microclimate regulation function of urban wetlands. Saaroni and $\mathrm{Ziv}$ analyzed the climate effect of a four-hectare pond located in Begin Park, Tel Aviv, Israel. They found that even small bodies of water within a $40 \mathrm{~m}$ range have a relieving effect on humans in daytime hours under both dry and humid weather conditions [22]. Kim et al. used observational data from 2003 to 2005 to investigate the changes in the local thermal environment associated with the restoration of an inner-city stream in Seoul, Korea. They estimated that after the stream was restored, the near-surface temperature averaged over the stream area dropped by $0.4{ }^{\circ} \mathrm{C}$, with the largest local temperature drop being $0.9^{\circ} \mathrm{C}$ [23]. Hou et al. developed a method of near-surface air temperature (NSAT) retrieval that employs Landsat Thematic Mapper images and examined the spatial relationship between NSAT and urban wetlands. They discovered that wetlands have an obvious influence on atmospheric temperature, which decreases as the distance from the wetland increases. Kochi is a fast-growing urban region in coastal South India interlaced by a network of canals and wetlands that is a part of the Vembanad Lake system [24]. Thomas and Zachariah investigated the UHI records of Kochi in summer and winter, and found that the UHI intensity is moderate compared with that observed in other cities in the region [25]. These studies confirmed that urban wetlands have a regulation function on the microclimate. However, numerous issues remain unanswered regarding the microclimate regulation function of urban wetlands, such as its link with the urban sprawl, its difference among land cover types in wetland regions, the stabilizing effect of wetlands on microclimate and how to quantify it, and the influence of season and weather factors on the said function.

Hangzhou, a city located in East China, has been undergoing rapid urbanization for the past 30 years. According to the China City Statistical Yearbook, the area of Hangzhou's urban construction land increased from $107 \mathrm{~km}^{2}$ in 1985 to $495 \mathrm{~km}^{2}$ in 2015. A large number of urban wetlands west of the city have been occupied by urban construction. To deepen the understanding on the microclimate regulation function of an urban wetland, this study analyzed the influence of urbanization of a suburb's wetlands on the local climate by carrying contrast observations of the protected wetland area (PW) and the former wetland area (FW) in Xixi wetland.

\section{Study Area}

Hangzhou, the capital of Zhejiang Province, is located in a subtropical monsoon region. Its climate belongs to humid subtropical climate (Cfa) according to Köppen climate classification [26], which characterized by hot, usually humid summers, and cool winters. Hangzhou is rich in wetland resources and has many famous wetlands, such as West Lake, Xixi, Qiantang River, and Grande Canal.

Xixi wetland, which is known as "the kidney of Hangzhou", is a rare urban secondary wetland located west of the city. Xixi previously covered an area of up to $60 \mathrm{~km}^{2}$, but has shrunk to $11 \mathrm{~km}^{2}$ because of the urbanization of Hangzhou in the past 30 years. Hangzhou Xixi National Wetland Park was constructed in 2005 to protect Xixi wetland. In 2009, Xixi was successfully included in the "List of Wetlands of International Importance" [27].

Xixi wetland mainly consists of fish ponds, rivers, lakes, and vegetation communities. The water body area accounts for approximately $70 \%$ of Xixi Wetland Park. The total length of the rivers in Xixi is about $110 \mathrm{~km}$. Xixi wetland has abundant animal and plant resources, including numerous national key protected animals and plants, like Loetes sinensis, Glycine soja, and Accipiter virgatus [28,29]. 


\section{Data and Methods}

\subsection{Field Observation}

\subsubsection{Observation Points}

This study divides the observation zone into two parts (Figure 1). One part is Hangzhou Xixi National Wetland Park, which retains the original landscape of wetlands. The other part is the northern side of the national wetland park, which was previously a part of Xixi wetland but is now an urban constructed land with some fragmentary water bodies and vegetation left. The former is called PW, while the latter is identified as FW. In each part of the observation zone, three observation points with different land cover types are selected: water body, vegetation, and impervious surface. Through contrast observations of PW and FW in Xixi wetland, this study aims to analyze the impact of wetland conversion to urban land cover on the local microclimate.
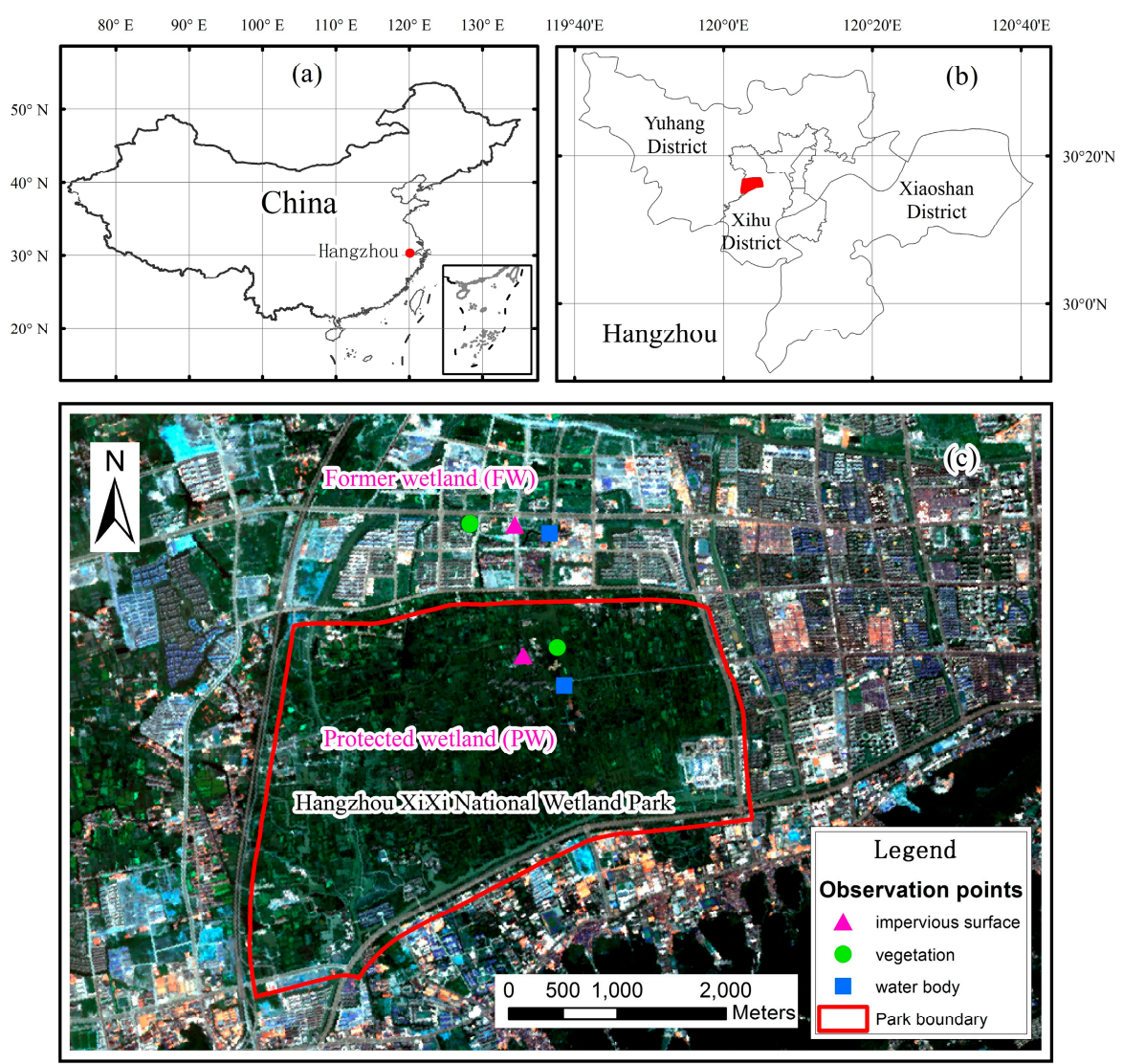

Figure 1. (a) Location of Hangzhou; (b) location of Hangzhou Xixi National Wetland Park; and (c) the distribution of meteorological observation points inside and outside of Hangzhou Xixi National Wetland Park.

\subsubsection{Observation Time}

Three continuous days with fine weather are chosen for each of the four seasons (spring, summer, autumn, and winter) for the field observation. The observation time for each day is from 8:00 a.m. to 6:00 p.m., and the meteorological parameters per hour are recorded.

\subsubsection{Observation Instruments and Parameters}

PH-II (Wuhan Xinpuhui Technology Co., Ltd., Wuhan, China) handheld meteorological stations are used to record the air temperature, relative humidity, wind direction, wind speed, and atmospheric 
pressure of each observation point. The observation accuracy of air temperature is $\pm 0.2{ }^{\circ} \mathrm{C}$, relative humidity is $\pm 3 \% R H$, and atmospheric pressure is $\pm 0.3 \mathrm{hPa}$. A Microtops II (Solar Light Company, Inc., Glenside, PA, USA.) portable multi-wavelength sun-photometer, with a $0.01 \mathrm{~W} / \mathrm{m}^{2}$ resolution and $1 \%-2 \%$ observation accuracy, is utilized to measure the solar radiation per hour.

\subsection{Human Comfort}

The comfort index of the human body is employed to calculate human comfort [30] and analyze the response of the human body to the changes of the meteorological elements. The formula is as follows:

$$
\text { CIHB }=1.8 t+32-0.55\left(1-\frac{h u}{100}\right) \times(1.8 t-26)-3.2 \sqrt{v}
$$

where $t$ is the air temperature $\left({ }^{\circ} \mathrm{C}\right), h u$ is the relative humidity $(\% \mathrm{RH})$, and $v$ is the wind speed $(\mathrm{m} / \mathrm{s})$.

Table 1 present what a certain value of human comfort index means.

Table 1. Grade standards of CIHB index [30].

\begin{tabular}{ccc}
\hline CIHB & Grade & Body Feeling \\
\hline$<25$ & -3 & chilly \\
$25 \sim 40$ & -2 & cold \\
$40 \sim 60$ & -1 & cool \\
$60 \sim 70$ & 0 & comfortable \\
$70 \sim 80$ & 1 & warm \\
$80 \sim 85$ & 2 & hot \\
$>85$ & 3 & heat \\
\hline
\end{tabular}

\section{Results}

The changes of the meteorological elements in the study area were obtained by processing the observation data.

\subsection{Air Temperature}

The air temperature in Xixi wetland showed an obvious seasonal difference (Figure 2). The average temperature of all observation points in spring, summer, autumn, and winter was 21.9, 36.4, 24.7, and $7.9^{\circ} \mathrm{C}$, respectively (Table 2). Meanwhile, the difference between summer and winter reached $28.54{ }^{\circ} \mathrm{C}$. The diurnal variation of air temperature in Xixi wetland was also apparent. The daily maximum temperature appeared between 1:00 p.m. and 2:00 p.m. and showed a single peak type. The average daily temperature difference in spring, summer, autumn, and winter was $9.3,6.3,6.4$, and $2.9^{\circ} \mathrm{C}$, respectively. Additionally, although the pattern of temperature variation of $\mathrm{PW}$ was similar to that of FW, certain differences still existed between them. Compared with FW, the air temperature of PW was generally lower and the variation range smaller, indicating that Xixi wetland has a microclimate regulation function.

Table 2. Average meteorological data for the three days of each season.

\begin{tabular}{|c|c|c|c|c|c|c|c|}
\hline Season & Item & $\begin{array}{c}\text { Air } \\
\text { Temperature } \\
\left({ }^{\circ} \mathrm{C}\right)\end{array}$ & $\begin{array}{c}\text { Relative } \\
\text { Humidity } \\
\text { (\%RH) }\end{array}$ & $\begin{array}{l}\text { Wind } \\
\text { Speed } \\
(\mathrm{m} / \mathrm{s})\end{array}$ & $\begin{array}{c}\text { Atmospheric } \\
\text { Pressure } \\
\text { (hPa) }\end{array}$ & $\begin{array}{c}\text { Solar } \\
\text { Radiation } \\
\left(\mathrm{W} / \mathrm{m}^{2}\right)\end{array}$ & $\begin{array}{l}\text { Cloud } \\
\text { Cover } \\
(n / 10)\end{array}$ \\
\hline \multirow{3}{*}{ April } & $A_{F W}$ & 22.1 & 44 & 0.2 & 1017.0 & \multirow{3}{*}{8.51} & \multirow{3}{*}{5.7} \\
\hline & $A_{P W}$ & 21.8 & 47 & 0.2 & 1017.2 & & \\
\hline & $\mathrm{A}_{\text {TOTAL }}$ & 21.9 & 46 & 0.2 & 1017.1 & & \\
\hline \multirow{3}{*}{ July } & $\mathrm{A}_{\mathrm{FW}}$ & 37.2 & 58 & 1.0 & 1004.0 & \multirow{3}{*}{23.82} & \multirow{3}{*}{2.29} \\
\hline & APW & 35.6 & 63 & 0.6 & 1004.2 & & \\
\hline & $\mathrm{A}_{\text {TOTAL }}$ & 36.4 & 60 & 0.8 & 1004.1 & & \\
\hline
\end{tabular}


Table 2. Cont.

\begin{tabular}{|c|c|c|c|c|c|c|c|}
\hline Season & Item & $\begin{array}{c}\text { Air } \\
\text { Temperature } \\
\left({ }^{\circ} \mathrm{C}\right) \\
\end{array}$ & $\begin{array}{c}\text { Relative } \\
\text { Humidity } \\
\text { (\%RH) }\end{array}$ & $\begin{array}{l}\text { Wind } \\
\text { Speed } \\
(\mathrm{m} / \mathrm{s})\end{array}$ & $\begin{array}{c}\text { Atmospheric } \\
\text { Pressure } \\
(\mathrm{hPa})\end{array}$ & $\begin{array}{c}\begin{array}{c}\text { Solar } \\
\text { Radiation } \\
\left(\mathrm{W} / \mathrm{m}^{2}\right)\end{array} \\
\end{array}$ & $\begin{array}{l}\text { Cloud } \\
\text { Cover } \\
(n / 10) \\
\end{array}$ \\
\hline \multirow{3}{*}{ October } & $A_{F W}$ & 25.3 & 56 & 0.4 & 1017.3 & \multirow{3}{*}{11.61} & \multirow{3}{*}{4.92} \\
\hline & $\mathrm{A}_{\mathrm{PW}}$ & 24.1 & 58 & 0.5 & 1017.4 & & \\
\hline & $\mathrm{A}_{\text {TOTAL }}$ & 24.7 & 57 & 0.5 & 1017.3 & & \\
\hline \multirow{3}{*}{ January } & $A_{F W}$ & 7.8 & 74 & 0.2 & 1025.6 & \multirow{3}{*}{0.66} & \multirow{3}{*}{8.58} \\
\hline & APW & 7.9 & 76 & 0.3 & 1025.8 & & \\
\hline & $\mathrm{A}_{\text {TOTAL }}$ & 7.8 & 75 & 0.2 & 1025.7 & & \\
\hline
\end{tabular}

Note: $A_{F W}$ is the average meteorological data for the three observation days of $F W ; A_{P W}$ is the average meteorological data for the three observation days of PW; $\mathrm{A}_{\mathrm{TOTAL}}$ is the average meteorological data for the three observation days of FW and PW. Cloud cover data was acquired from Zhejiang Institute of Meteorological Sciences; its value equal to 0 means a cloudless sky, while 10 means clouded over.

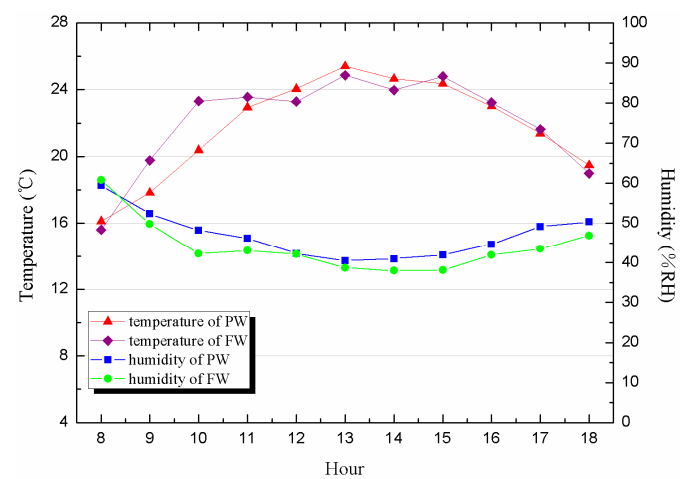

(a)

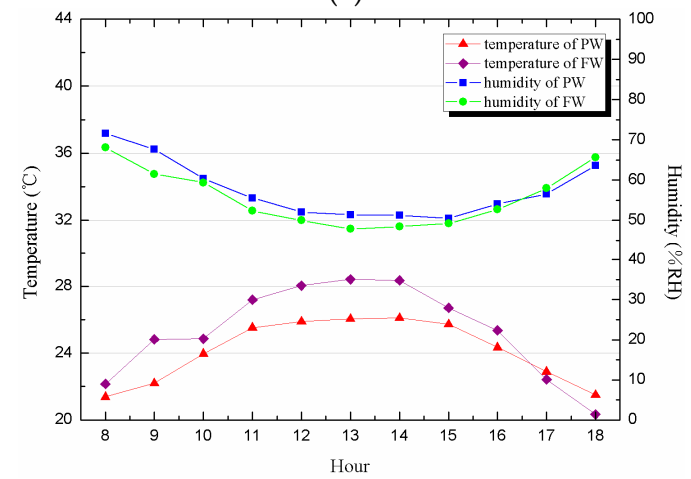

(c)

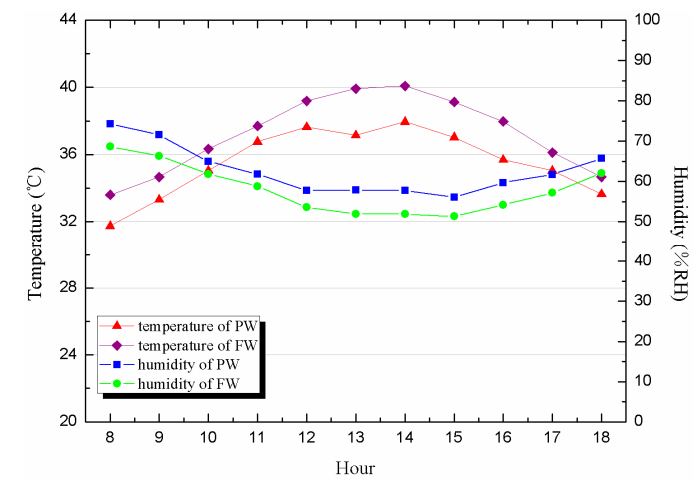

(b)

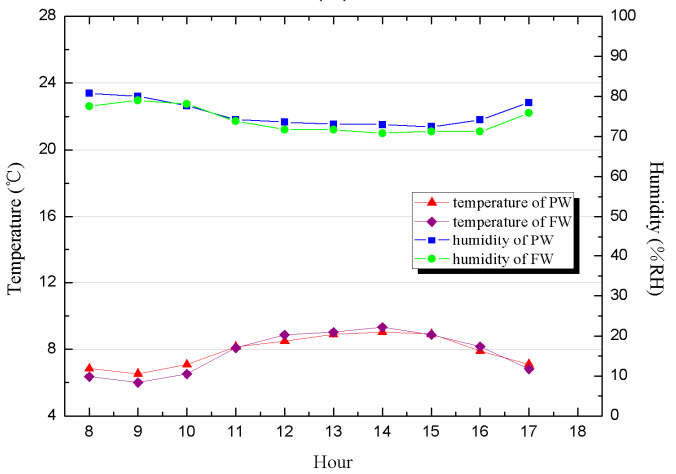

(d)

Figure 2. Diurnal variations of air temperature and relative humidity in four seasons in the study area. (a) Spring; (b) summer; (c) autumn; and (d) winter.

\subsection{Relative Humidity}

The relative humidity in Xixi wetland showed a few seasonal differences (Figure 2). The average relative humidity of all observation points was $46 \% \mathrm{RH}, 60 \% \mathrm{RH}, 57 \% \mathrm{RH}$, and $75 \% \mathrm{RH}$ in spring, summer, autumn, and winter, respectively (Table 2), with a maximal seasonal difference of $29.4 \% \mathrm{RH}$. The diurnal variation of relative humidity was also shown as a U curve, and the daily minimum humidity appeared between 2:00 p.m. and 3:00 p.m. The average diurnal ranges were $20.9 \%$ RH, $17.8 \% \mathrm{RH}, 20.7 \% \mathrm{RH}$, and $8.3 \% \mathrm{RH}$ in spring, summer, autumn, and winter. The relative humidity in winter was more stable than in other seasons because Hangzhou is located in the eastern coastal region of China, and the prevailing wind comes from the ocean in summer and inland in winter. Moreover, the relative humidity of PW was generally higher than FW, indicating that Xixi wetland possesses a humidifying function. 


\subsection{Relationship between Temperature and Humidity}

The correlation coefficients of air temperature and relative humidity were less than -0.90 in the four seasons, thus showing a high negative correlation. The correlation coefficients of spring and winter were the highest, reaching -0.97 and -0.96 respectively. By contrast, the correlation coefficient of autumn was the lowest at only -0.90 . These results are attributed to the fact that although evaporation speeds up and leads to an increase in water vapor pressure when air temperatures rise, the increase in saturation vapor pressure is faster, which ultimately reduces the relative humidity, and vice versa.

\section{Discussions}

\subsection{Impact of Urbanization on Microclimate}

Xixi wetland in the west of Hangzhou previously covered enormous acreages of approximately $60 \mathrm{~km}^{2}$ of farming wetlands [31]. However, since the 1990s, most of those wetlands were turned into urban land cover, with the exception of the strictly-protected Hangzhou Xixi National Wetland Park. Therefore, the impact of urbanization on the microclimate can be determined by comparing the meteorological parameters between PW and FW.

This study calculated the difference between the meteorological parameters of PW and FW and found the following results (Figure 3).

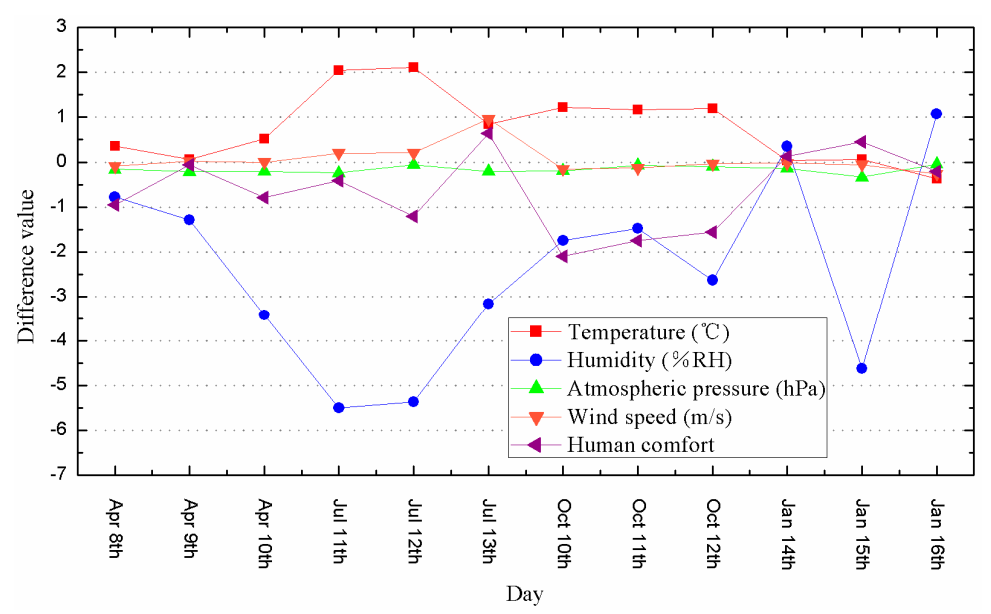

Figure 3. Differences between the meteorological parameters of FW and PW. All of the difference values are FW minus PW.

Temperature. The average temperature of all observation points in $\mathrm{FW}$ is $23.11^{\circ} \mathrm{C}$, which is $0.77^{\circ} \mathrm{C}$ higher than that in $\mathrm{PW}\left(22.34^{\circ} \mathrm{C}\right)$. As for the seasonal distribution, the average temperature of FW is higher than that of PW in spring, summer, and autumn, with the maximum temperature difference of up to $1.67^{\circ} \mathrm{C}$ appearing in summer. These findings indicated that Xixi wetland serves a cool-island effect in warm seasons and a warm-island effect in cold seasons. In fact, the cooling effect of Xixi wetland is $0.86{ }^{\circ} \mathrm{C}$ higher in summer compared with the observation results of Chang et al. in an urban park in Taipei [15]. The increased cooling effect of Xixi wetland may be caused by the percentage of water bodies in Xixi wetland being larger than that in the urban park in Taipei.

Relative humidity. The average relative humidity of all observation points in FW is $58 \% \mathrm{RH}$, which is $2.4 \% \mathrm{RH}$ lower than that in PW $(60.4 \% \mathrm{RH})$. As for the seasonal distribution, the average humidity of FW is lower than that of PW in all seasons. The maximum humidity difference of up to $4.7 \%$ RH appeared in summer, whereas the minimum humidity difference of only $1.1 \% \mathrm{RH}$ occurred in winter. These findings imply that Xixi wetland has a humidifying function in all seasons.

Atmospheric pressure. The atmospheric pressure of FW is generally lower than that of PW, but the seasonal variation is not obvious. 
Wind speed. The average wind speed of FW is $0.46 \mathrm{~m} / \mathrm{s}$ higher than that of $\mathrm{PW}$ in summer, but has no considerable difference in other seasons.

Human comfort. The human comfort of FW is lower than that of PW in spring, summer, and autumn, with the maximum difference of up to 1.81 appearing in autumn. The human comfort of FW is slightly higher than that of PW in winter (0.12).

\subsection{Microclimate Effects of Different Land Cover Types}

Previous studies pay little attention to the land cover types in wetland regions, except for the water bodies [22]. However, in most cases, water bodies, vegetation, and buildings are inseparable in the construction of urban wetland landscapes. Therefore, exploring the effects of various land cover types in wetland landscapes on the microclimate is necessary to present more pertinent criteria on urban wetland landscape planning. The different effects of each land cover type on the microclimate between FW and PW can be determined by comparing the meteorological parameters of each land cover type.

\subsubsection{Vegetation}

Air temperature. Figure 4 shows that the air temperature of vegetation in FW is mostly higher than that in PW, indicating that the wetland environment can enhance the microclimate regulation function of vegetation. In addition, previous studies demonstrated that vegetation can reduce the temperature of its surrounding area mainly by shading and evapotranspiration [32]. Therefore, the microclimate regulation function of vegetation will clearly have a seasonal variation for plants growth [32], as confirmed by the results of the present study. The main species of trees in Xixi wetland are Diospyros kaki Thunb, Pterocarya stenoptera C. DC, Salix matsudana Koidz, and Paulownia Sieb. These species have great seasonal variation on vegetation coverage and evapotranspiration and contribute to the seasonal change of the microclimate regulation effects of vegetation.

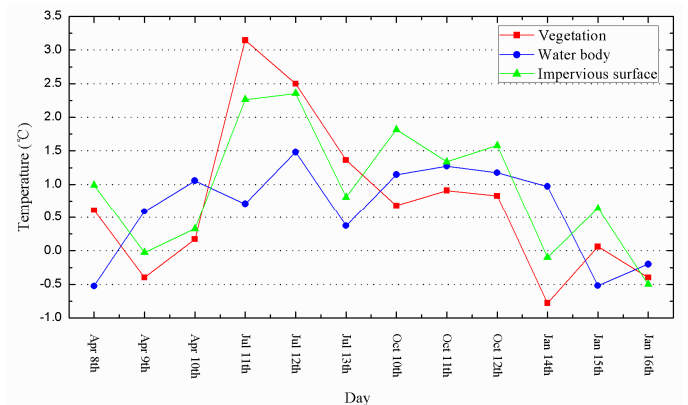

(a) Temperature difference

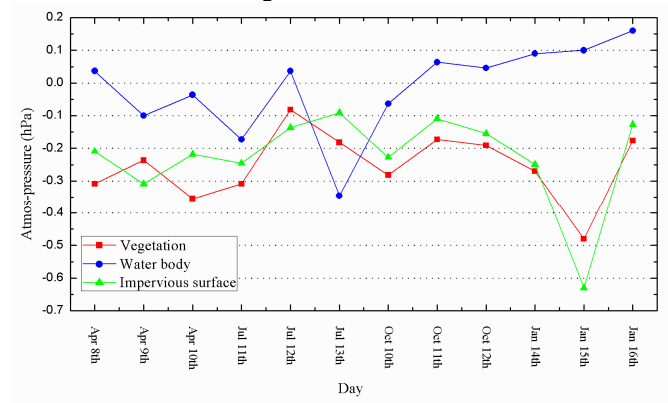

(c) Atmospheric pressure difference

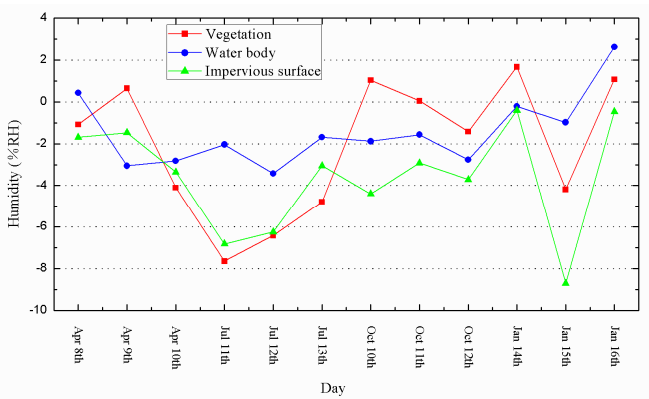

(b) Humidity difference

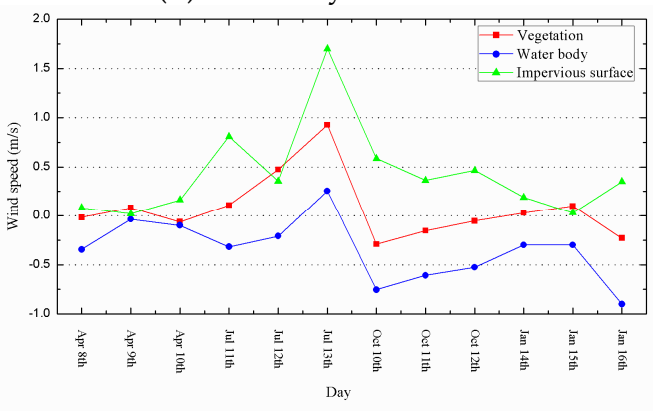

(d) Wind speed difference

Figure 4. Different effects of each land cover type between the meteorological parameters of FW and PW. All of the difference values are FW minus PW. (a) Temperature difference of each land cover type between FW and PW; (b) humidity difference of each land cover type between FW and PW; (c) atmospheric pressure difference of each land cover type between FW and PW; and (d) wind speed difference of each land cover type between FW and PW. 
Relative humidity. The variation tendencies of humidity and temperature generally appear as a negative correlation, with the correlation coefficient of -0.79 . Figure 4 shows that the humidity of vegetation in FW is mostly lower than that in PW, with the maximal difference of up to $7.7 \% \mathrm{RH}$ appearing in summer. One reason for this difference is that the water body in the Xixi Wetland Park helps increase the relative humidity. Plant growth is also more exuberant in wetlands, thereby significantly increasing evapotranspiration [33] and relative humidity.

Atmospheric pressure. The atmospheric pressure of vegetation in FW is generally lower than that in PW, but the variation is not obvious.

Wind speed. The average wind speed of vegetation in FW is $0.93 \mathrm{~m} / \mathrm{s}$ higher than that in $\mathrm{PW}$ in summer, but has no considerable difference in other seasons. The increase of wind speed in FW is due to the larger amplitude of climate change, more airflow, and the effect of narrow urban streets [34].

\subsubsection{Water Body}

Air temperature. Figure 4 illustrates that the air temperature of water bodies in FW is usually higher than in PW. This result, which is in accordance with previous studies [35], indicates that acreage crucially influences the temperature regulation of wetlands. As for the seasonal variation, the temperature difference between FW and PW is the biggest in summer but the smallest in winter.

Relative humidity. Figure 4 exhibits that the humidity of water bodies in FW is generally lower than that in PW, denoting that acreage also significantly affects the humidity regulation of wetlands. The larger the acreage is, the stronger the humidity regulation function of a water body. Moreover, the variation tendency of a water body's humidity and temperature is similar with that of vegetation, which has a correlation coefficient of -0.67 , because of the relationship between temperature and relative humidity.

Atmospheric pressure and wind speed. The results show no significant differences between FW and PW in atmospheric pressure and wind speed.

\subsubsection{Impervious Surface}

Air temperature. Figure 4 shows that the air temperature of impervious surfaces in FW is mostly higher than that in PW. The air temperature of impervious surfaces is $0.45^{\circ} \mathrm{C}$, which is higher than that of the water bodies in FW and just $0.12{ }^{\circ} \mathrm{C}$ higher in PW. This finding indicated that the wetland environment can bring some cooling effects on impervious surfaces. As for the seasonal variation, the temperature difference between FW and PW is the largest in summer and the smallest in winter.

Relative humidity. The variation tendency of the humidity and temperature of impervious surfaces generally appeared as a negative correlation, with a correlation coefficient of -0.64 . The absolute value of the impervious surfaces' correlation coefficient is smaller than that of water body and vegetation, because impervious surfaces do not have a microclimate regulation function, which is only influenced by adjacent water bodies and vegetation. Figure 4 also displays that the humidity of impervious surfaces in FW are usually lower than that in PW, with the biggest difference of up to $8.7 \%$ RH between FW and PW appearing in winter on 15 January. However, considering that the humidity difference between the adjacent two days (14 January and 16 January) is small, the result is more likely to be caused by incidental factors. The greatest humidity difference between FW and PW appeared in summer from the aspect of each season's average value.

Atmospheric pressure. Figure 4 presents that the atmospheric pressure of impervious surfaces in FW is mostly lower than that in PW, but the difference is not obvious.

Wind speed. The wind speed of impervious surfaces in FW is generally higher than that in PW. The maximum difference is $1.7 \mathrm{~m} / \mathrm{s}$, which is greater than any other land cover type, because of the larger amplitude of climate change of the impervious surfaces and the effect of narrow urban streets. 


\subsection{Microclimate Stability Function of Xixi Wetland}

The microclimate stability function of wetlands has been referred to in various literature [36-38], but related quantitative research is rare. This section presents the quantitative analysis of the stabilizing effects of wetlands on the microclimate.

\subsubsection{Overall Stabilizing Effect}

The coefficient of variation (CV) for all observation points in FW and PW for each observation day was calculated to analyze the overall stability of meteorological factors in FW and PW. Table 3 show that all CV of the meteorological factors in FW are higher than those in PW, indicating that Xixi wetland has a stabilizing effect on the microclimate in all seasons. As for a single meteorological factor, the stabilizing effect of wetlands on wind speed is the most obvious, with the difference of CV up to $33.8 \%$, whereas the stabilizing effect on atmospheric pressure shows almost no difference.

Table 3. Overall CV of meteorological factors in FW and PW.

\begin{tabular}{cccccc}
\hline Item & $\begin{array}{c}\text { Air } \\
\text { Temperature (\%) }\end{array}$ & $\begin{array}{c}\text { Relative } \\
\text { Humidity (\%) }\end{array}$ & $\begin{array}{c}\text { Atmospheric } \\
\text { Pressure (\%) }\end{array}$ & $\begin{array}{c}\text { Wind } \\
\text { Speed (\%) }\end{array}$ & $\begin{array}{c}\text { Human } \\
\text { Comfort (\%) }\end{array}$ \\
\hline $\begin{array}{c}\text { Protected wetland } \\
\text { (PW) }\end{array}$ & 45.0 & 18.6 & 0.8 & 95.8 & -80.6 \\
\hline $\begin{array}{c}\text { Former wetland } \\
\text { (FW) }\end{array}$ & 46.5 & 20.0 & 0.8 & 129.6 & -72.8 \\
\hline FW minus PW & 1.4 & 1.5 & 0.0 & 33.8 & 7.8 \\
\hline
\end{tabular}

\subsubsection{Stabilizing Effect of Each Land Cover Type}

The CV of each land cover type in FW and PW for every observation day was computed to analyze the stabilizing effect of each land cover type on the microclimate. Table 4 illustrates that all $\mathrm{CV}$ of the land cover types in FW are higher than those in PW, indicating that the Xixi wetland has a stabilizing effect on microclimate for all land cover types. As for a single meteorological factor, the stabilizing effect of wetland vegetation is the most obvious on temperature, in which the difference of the CV between FW and PW is up to $2.99 \%$. Meanwhile, the stabilizing effect of water bodies is the most obvious on humidity and wind speed, in which the difference of CV between FW and PW for each cover type is $2.0 \%$ and $104.6 \%$, respectively.

Table 4. CV of each land cover type's meteorological factors in FW and PW.

\begin{tabular}{cccccc}
\hline \multicolumn{2}{c}{ Observation Points } & $\begin{array}{c}\text { Air } \\
\text { Temperature (\%) }\end{array}$ & $\begin{array}{c}\text { Relative } \\
\text { Humidity (\%) }\end{array}$ & $\begin{array}{c}\text { Atmospheric } \\
\text { Pressure (\%) }\end{array}$ & $\begin{array}{c}\text { Wind } \\
\text { Speed (\%) }\end{array}$ \\
\hline \multirow{2}{*}{$\begin{array}{c}\text { Protected wetland } \\
\text { (PW) }\end{array}$} & vegetation & 45.3 & 18.7 & 0.8 & 96.3 \\
& impervious surface & 46.5 & 20.3 & 0.8 & 81.2 \\
& water body & 47.2 & 18.2 & 0.8 & 73.0 \\
\hline \multirow{2}{*}{$\begin{array}{c}\text { Former wetland } \\
\text { (FW) }\end{array}$} & vegetation & 48.3 & 20.1 & 0.8 & 155.5 \\
& impervious surface & 47.8 & 21.3 & 0.8 & 85.8 \\
\hline
\end{tabular}

\subsection{Impact Factors}

To understand the impact mechanism of meteorological factors on the microclimate effect of wetlands, this section presents the differences between each meteorological factor of FW and PW as an explained variable and considers the average value of all meteorological factors as explanatory variables. The impact factors of a wetland's microclimate effect are also discussed by means of stepwise regressions. 


\subsubsection{Temperature Difference between FW and PW}

Table 5 shows that air temperature significantly affects the cooling effect of wetlands. The higher the air temperature is, the greater the temperature difference between FW and PW and the stronger the wetland's cooling effect. Moreover, humidity and atmospheric pressure have some positive effects on a wetland's cooling effect. However, wind speed has certain negative impacts on the cooling effect of wetlands, an outcome that means the greater the wind speed is, the weaker the wetland's cooling effect. This phenomenon is due to the increase of wind speed, which strengthens the heat exchange within the local scope and reduces the unbalanced distribution of heat.

Table 5. Regression analysis results of the temperature difference between FW and PW (FW minus PW).

\begin{tabular}{cccccc}
\hline Explanatory Variables & Coefficients & std.error & Standard Coefficients & $\boldsymbol{t}$ & sig. \\
\hline Constant & -96.231 & 32.992 & & -2.917 & 0.022 \\
Air temperature & 0.150 & 0.027 & 2.048 & 5.486 & 0.001 \\
Relative humidity & 0.024 & 0.009 & 0.342 & 2.491 & 0.042 \\
Atmospheric pressure & 0.091 & 0.032 & 0.960 & 2.883 & 0.024 \\
Wind speed & -0.694 & 0.280 & -0.290 & -2.477 & 0.042 \\
\hline
\end{tabular}

Note: $R=0.96, R^{2}=0.92, F$ (sig.) $=20.655(0.001)$.

\subsubsection{Humidity Difference between FW and PW}

Table 6 illustrates that solar radiation highly influences the humidifying effect of wetlands. The stronger the solar radiation is, the greater the humidity difference between FW and PW and the stronger the wetland's humidifying effect. This phenomenon is due to the increase of solar radiation, which strengthens the evaporation in PW. Higher evaporation means more moisture in vapor form, which would increase the humidity of PW and enlarge the humidity difference between FW and PW.

Table 6. Regression analysis results of the humidity difference between FW and PW (PW minus FW).

\begin{tabular}{cccccc}
\hline Explanatory Variables & Coefficients & std.error & Standard Coefficients & $t$ & sig. \\
\hline Constant & 0.770 & 0.778 & & 0.989 & 0.346 \\
Solar radiation & 0.139 & 0.052 & 0.646 & 2.676 & 0.023 \\
\hline \multicolumn{7}{c}{ Note: $R=0.65, R^{2}=0.42, F($ sig. $)=7.161(0.023)}$.
\end{tabular}

\subsubsection{Wind Speed Difference between FW and PW}

Table 7 demonstrates that atmospheric pressure crucially influences the wind speed difference between FW and PW. The higher the atmospheric pressure is, the greater the wind speed difference between FW and PW.

Table 7. Regression analysis results of the wind speed difference between FW and PW (PW minus FW).

\begin{tabular}{cccccc}
\hline Explanatory Variables & Coefficients & std.error & Standard Coefficients & $\boldsymbol{t}$ & sig. \\
\hline Constant & -27.949 & 8.213 & & -3.403 & 0.007 \\
Atmospheric pressure & 0.027 & 0.008 & 0.732 & 3.397 & 0.007 \\
\hline
\end{tabular}

Note: $R=0.732, R^{2}=0.536, F$ (sig.) $=11.539(0.007)$.

\section{Conclusions}

\subsection{Overall Impact of Urbanization on Local Microclimate}

The results of this study show that the urbanization of suburban wetlands has an overall impact on the local microclimate and decreases human comfort. In the FW after urbanization, the following results were found: (1) the average temperature increased by $0.77^{\circ} \mathrm{C}$ in four seasons, with the most 
intense increase of $1.67^{\circ} \mathrm{C}$ occurring in summer; (2) the average relative humidity reduced by $2.4 \% \mathrm{RH}$ in four seasons, with the highest decrease of $4.7 \% \mathrm{RH}$ occurring in summer; (3) the average wind speed increased by $0.46 \mathrm{~m} / \mathrm{s}$ in summer, but had no significant changes in other seasons; and (4) the human comfort of FW is lower than that of PW in spring, summer, and autumn, with the maximum difference of up to 1.81 appearing in autumn. Since the 1990s, the UHI effect of Hangzhou has gradually strengthened and the urban climate condition has worsened. These outcomes have a direct relationship with the conversion of wetland to urban construction land in Hangzhou. In the future, we must control the pace of urban sprawl during economic development. In addition, we should take some measures to protect suburbs' wetlands. For example, we can demarcate the ecological protection red line of wetlands in urban planning.

\subsection{Impact of Urbanization on Each Land Cover Type}

(1) Urbanization reduces the microclimate regulation function of vegetation and water bodies. In comparison with the corresponding land cover type in $\mathrm{PW}$, the average temperature and humidity of vegetation and water bodies in FW are 0.72 and $0.63{ }^{\circ} \mathrm{C}$ higher and $2.1 \% \mathrm{RH}$ and $1.5 \%$ RH lower, respectively.

(2) In comparison with PW, the acreages of vegetation and water bodies in FW are smaller, their distributions are scattered, and their microclimate regulation functions are weaker. Therefore, acreage and spatial distribution affect the microclimate regulation function of vegetation and water bodies. In the process of urban development, we not only need to maintain a certain amount of urban wetlands, but also need to optimize its spatial distribution with relative concentration.

(3) The air temperature of impervious surfaces is $0.45^{\circ} \mathrm{C}$ higher than that of water bodies in FW but just $0.12{ }^{\circ} \mathrm{C}$ higher in PW. This result indicates that the wetland environment can bring some cooling effects on impervious surfaces.

(4) The maximum differences between the meteorological elements of FW and PW mainly appear in summer, indicating that the maximum effects of microclimate regulation of wetlands occur in summer. Hangzhou is very hot in summer, which highlights the importance of urban wetland's microclimate regulation function. Therefore, the cities that have similar climate with Hangzhou should pay more attention to urban wetland protection, so as to take full advantage of wetland's microclimate regulation function.

\subsection{Microclimate Stability Function of Wetlands}

(1) Overall stabilizing effect. All CV of the meteorological factors in FW are higher than those in PW, implying that Xixi wetland has a stabilizing effect on the microclimate in all seasons.

(2) Stabilizing effect of each land cover type. The stabilizing effect of wetland vegetation is the most obvious on temperature, whereas that of water bodies is the most obvious on humidity and wind speed.

\subsection{Impact Factors}

This study discussed the impact factors of a wetland's microclimate effect by means of stepwise regression. The following conclusions can be drawn from the results.

(1) Air temperature, humidity, and atmospheric pressure have positive influences on a wetland's cooling effect, with the impact of air temperature as the biggest influence. However, wind speed has a negative impact on a wetland's cooling effect.

(2) Solar radiation has positive effects on a wetland's humidifying effect. The stronger the solar radiation is, the bigger the humidity difference between FW and PW and the stronger the wetland's humidifying effect.

(3) Atmospheric pressure significantly affects the wind speed difference between FW and PW. The higher the atmospheric pressure is, the greater the wind speed difference between FW and PW. 
These findings can be used to carry out the spatial planning of urban wetlands. For example, if we want to construct a wetland park, then we can choose a place that can make full use of wetland's microclimate regulation function according to the spatial differences of the meteorological parameters.

Acknowledgments: This work was supported by Fundamental Research Funds for the Central Universities (SWU115003) and National Natural Science Foundation of China (No. 41101039). We would also like to thank the students of Hangzhou Normal University for their field observation work.

Author Contributions: The authors synergistically contributed to this work. In particular, Wei Zhang is the designer of the research work and contributed to the experimental campaign and the paper writing. Yubi Zhu is the coordinator of the research group and contributed to the research design. Jingang Jiang contributed to the in-field monitoring campaigns and to the results' post-processing. All authors have read and approved the final manuscript.

Conflicts of Interest: The authors declare no conflict of interest.

\section{References}

1. Kurucu, Y.; Chiristina, N.K. Monitoring the impacts of urbanization and industrialization on the agricultural land and environment of the Torbali, Izmir region, Turkey. Environ. Monit. Assess. 2008, 136, $289-297$. [CrossRef] [PubMed]

2. Zhou, H.; Shi, P.; Wang, J.; Yu, D.; Gao, L. Rapid urbanization and implications for river ecological services restoration: Case study in Shenzhen, China. Am. Soc. Civ. Eng. 2015, 137, 121-132. [CrossRef]

3. Grimm, N.B.; Foster, D.; Groffman, P.; Grove, J.M.; Hopkinson, C.S.; Nadelhoffer, K.J.; Pataki, D.E.; Peters, D.P.C. The changing landscape: Ecosystem responses to urbanization and pollution across climatic and societal gradients. Front. Ecol. Environ. 2008, 6, 264-272. [CrossRef]

4. Brennan, E.M. Population, urbanization, environment, and security: A summary of the issues. Environ. Chang. Secur. Proj. Rep. 1999, 5, 4-14.

5. Ren, L.; Cui, E.; Sun, H. Temporal and spatial variations in the relationship between urbanization and water quality. Environ. Sci. Pollut. Res. 2014, 21, 13646-13655. [CrossRef] [PubMed]

6. Tan, M.; Li, X.; Xie, H.; Lua, C. Urban land expansion and arable land loss in China-A case study of Beijing-Tianjin-Hebei region. Land Use Policy 2005, 22, 187-196. [CrossRef]

7. Deng, X.; Huang, J.; Rozelle, S.; Zhang, J.; Li, Z. Impact of urbanization on cultivated land changes in China. Land Use Policy 2015, 45, 1-7. [CrossRef]

8. Fann, N.; Lamson, A.D.; Anenberg, S.C.; Wesson, K.; Risley, D.; Hubbell, B.J. Estimating the national public health burden associated with exposure to ambient $\mathrm{PM}_{2.5}$ and ozone. Risk Anal. 2012, 32, 81-95. [CrossRef] [PubMed]

9. Rizwan, A.M.; Dennis, L.Y.C.; Liu, C. A review on the generation, determination and mitigation of urban heat island. J. Environ. Sci. 2008, 20, 120-128. [CrossRef]

10. Unger, J. Urban-rural air humidity differences in Szeged, Hungary. Int. J. Climatol. 1999, 19, 1509-1515. [CrossRef]

11. Unkašević, M.; Jovanović, O.; Popović, T. Urban-suburban/rural vapour pressure and relative humidity differences at fixed hours over the area of Belgrade city. Theor. Appl. Climatol. 2001, 68, 67-73. [CrossRef]

12. Cheng, M.T.; Tsai, Y.I. Characterization of visibility and atmospheric aerosols in urban, suburban, and remote areas. Sci. Total Environ. 2000, 263, 101-114. [CrossRef]

13. Huff, F.A.; Changnon, S.A., Jr. Precipitation modification by major urban areas. Bull. Am. Meteorol. Soc. 1973, 54, 1220-1220. [CrossRef]

14. Ji, W. Understanding urban wetland dynamics: Cross-scale detection and analysis of remote sensing. Int. J. Remote Sens. 2015, 36, 1763-1788. [CrossRef]

15. Chang, C.R.; Li, M.H.; Chang, S.D. A preliminary study on the local cool-island intensity of Taipei city parks. Landsc. Urban Plan. 2007, 80, 386-395. [CrossRef]

16. Costanza, R.; d'Arge, R.; De Groot, R.; Farber, S.; Grasso, M.; Hannon, B.; Limburg, K.; Naeem, S.; O’Neill, R.V.; Paruelo, J.; et al. The value of the world's ecosystem services and natural capital. Nature 1997, 387, 253-260. [CrossRef] 
17. Gou, Q.Q.; Qu, J.J.; Han, Z.W. Analysis of the microclimate and $\mathrm{CO}_{2}$ flux characteristics in arid desert wetland ecosystem in summer: A case study in Xihu desert wetland, Dunhuang, China. J. Earth Syst. Sci. 2014, 123, 1491-1499. [CrossRef]

18. Nakayama, T.; Fujita, T. Cooling effect of water-holding pavements made of new materials on water and heat budgets in urban areas. Landsc. Urban Plan. 2010, 96, 57-67. [CrossRef]

19. Laird, N.F.; Kristovich, D.A.R.; Liang, X.Z.; Arritt, R.W.; Labas, K. Lake Michigan lake breezes: Climatology, local forcing, and synoptic environment. J. Appl. Meteorol. 2001, 40, 409-424. [CrossRef]

20. Kodama, Y.; Eaton, F.; Wendler, G. The influence of Lake Minchumina, Interior Alaska, on its surroundings. Arch. Meteorol. Geophys. Bioclimatol. Ser. B 1983, 33, 199-218. [CrossRef]

21. Carol, E.; Braga, F.; Lio, C.D.; Kruse, E.; Tosi, L. Environmental isotopes applied to the evaluation and quantification of evaporation processes in wetlands: A case study in the Ajó Coastal Plain wetland, Argentina. Environ. Earth Sci. 2015, 74, 5839-5847. [CrossRef]

22. Saaroni, H.; Ziv, B. The impact of a small lake on heat stress in a Mediterranean urban park: The case of Tel Aviv, Israel. Int. J. Biometeorol. 2003, 47, 156-165. [PubMed]

23. Kim, Y.H.; Ryoo, S.B.; Baik, J.J.; Park, I.S.; Koo, H.J.; Nam, J.C. Does the restoration of an inner-city stream in Seoul affect local thermal environment? Theor. Appl. Climatol. 2008, 92, 239-248. [CrossRef]

24. Hou, P.; Chen, Y.; Qiao, W.; Cao, G.; Jiang, W.; Li, J. Near-surface air temperature retrieval from satellite images and influence by wetlands in urban region. Theor. Appl. Climatol. 2013, 111, 109-118. [CrossRef]

25. Thomas, G.; Zachariah, E.J. Urban heat island in a tropical city interlaced by wetlands. J. Environ. Sci. Eng. 2011, 5, 234-240.

26. Peel, M.C.; Finlayson, B.L.; Mcmahon, T.A. Updated world map of the Köppen-Geiger climate classification. Hydrol. Earth Syst. Sci. 2007, 4, 439-473. [CrossRef]

27. Li, Y.F.; Liu, H.Y.; Cai, C.X.; Li, Y.L.; Sun, Y.M. The disturbance effect of the surroundings on the water environmental health of urban wetland park: A case study on Xixi Wetland Park, China. Geogr. Res. 2015, 34, 851-860. (In Chinese)

28. Li, R.; Rong, L. Ecotourism carrying capacity of Hangzhou Xixi National Wetland Park in China. Chin. J. Appl. Ecol. 2007, 18, 2301-2307. (In Chinese)

29. Wang, G.X.; Wang, R.S.; Mao, C.H. Bad tourist behaviors and their environmental impacts on Xixi National Wetland Park in Hangzhou. Chin. J. Appl. Ecol. 2009, 20, 1423-1430. (In Chinese)

30. Yu, G.K.; Xu, M.; Gao, P.; Huang, L.; Luo, Y.; Ling, Y. Study on physical background of comfort index of human body anomaly in winter and summer in Jiangsu province. Meteorol. Mon. 2012, 38, 593-600. (In Chinese)

31. Tong, D.Q. The exploration of preservation and utilization of wetland tourist resource. Bus. Econ. Adm. 2006, 4,77-79. (In Chinese)

32. Cao, X.; Onishi, A.; Chen, J.; Imura, L. Quantifying the cool island intensity of urban parks using ASTER and IKONOS data. Landsc. Urban Plan. 2010, 96, 224-231. [CrossRef]

33. Guo, Y.D. Influence of Deyeuxia angustifolia vegetation on the evapotranspiration of mire in the Sanjiang plain. Wetl. Sci. 2008, 6, 392-397. (In Chinese)

34. Johnson, G.T.; Hunter, L.J. Some insights into typical urban canyon airflows. Atmos. Environ. 1999, 33, 3991-3999. [CrossRef]

35. Sun, R.; Chen, A.; Chen, L.; Lü, Y. Cooling effects of wetlands in an urban region: The case of Beijing. Ecol. Indic. 2012, 20, 57-64. [CrossRef]

36. Peng, X.F.; Sun, X.; Yuan, S.X.; Sun, R.Y.; Chen, Z.H. Landscape characteristics and microclimatic effects of the urban wetlands in Guangzhou city. Ecol. Environ. 2008, 17, 2289-2296. (In Chinese)

37. Raney, P.A.; Fridley, J.D.; Leopold, D.J. Characterizing microclimate and plant community variation in wetlands. Wetlands 2014, 34, 43-53. [CrossRef]

38. Cui, L.J.; Kang, X.M.; Zhao, X.S.; Li, W.; Ma, M.-Y.; Zhang, M.; Wei, Y.-Y. Spatiotemporal variation in the microclimate effects of typical urban wetland in Beijing. Chin. J. Ecol. 2015, 34, 212-218. (In Chinese)

(C) 2016 by the authors; licensee MDPI, Basel, Switzerland. This article is an open access article distributed under the terms and conditions of the Creative Commons Attribution (CC-BY) license (http://creativecommons.org/licenses/by/4.0/). 